\title{
The LC/MARC Record As a National Standard
}

The desire to promote exchange of bibliographic data has given rise to a rather cacophonous debate concerning MARC as a "standard," and the definition of a MARC compatible record. Much of the confusion has arisen out of a failure to carefully separate the intellectual content of a bibliographic record, the specific analysis to which it is subjected in an LC/MARC format, and its physical representation on magnetic tape. In addition, there has been a tendency to obscure the different requirements of users and creators of machine-readable bibliographic data. In general, the standards making process attempts to find a consensus among both groups based on existing practice. The process of standardization is rarely one which relies on enlightened legislation. Rather, a more pragmatic approach is taken based on an evaluation of the costs to manufacturers weighed against costs to consumers. Even this modest approach is not invested with lasting wisdom. ANSI standards, for example, are subject to quinquennial review.

Standards, as already pointed out, have as their basis common acceptance of conventions. Thus, it might prove useful to examine the conventions employed in an LC/MARC record. The most important of these is the Anglo-American Cataloging Rules as interpreted by LC. The use of these rules for descriptive cataloging and choice of entry is universal enough that they may safely be considered a standard. Similar comments may be made concerning the subject headings used in the dictionary catalog of the Library of Congress. The physical format within which machine-readable bibliographic data may be transmitted is accepted as a codified national and international standard (ANSI Z39.2-1971 and ISO 2709-1973 (E)). This standard, which is only seven pages in length, should be carefully read by anyone seriously concerned with the problems of bibliographic data interchange. ANSI Z39.2 is quite different from the published LC/ MARC formats. It defines little more than the structure of a variable length record. Simply stated, ANSI Z39.2 specifies only that a record shall contain a leader specifying its physical attributes, a directory for identifying elements within the record by numeric tag (the values of the tags are not defined), and optionally, additional designators which may be used to provide further information regarding fields and subfields. This structure is completely general. Within this same structure one could transmit book 
orders, a bibliographic record, an abstract, or an authority record by adopting specific conventions regarding the interpretation of numeric tags.

Thus, we come to the crux of the problem, the meanings of the content designators. Content designators (numeric tags, subfields, delimiters, etc.) are not synonymous with elements of bibliographic description; rather, they represent the level of explicitness we wish to achieve in encoding a record. It might safely be said that in the most common use of a MARC record-card production-scarcely more than the paragraph distinctions on an LC card are really necessary. If we accept such an argument, then we can simply define compatibility with LC/MARC by defining compatibility in terms of a particular class of applications, e.g., card, book, or CRT catalog creation. A record may be said to be compatible with LC/MARC if a system which accepts a record as created by $L C$ produces from the compatible record products not discernibly different from those created from an LC/MARC record.

Thus, what is called for is a family of standards all downwardly compatible with LC/MARC, employing ANSI Z39.2 as a structural base. This represents the only rational approach. The alternative is to accept LC/ MARC conventions as worthy of veneration as artistic expression.

S. Michael Malinconico 